\title{
Genetic Diversity and Relationships of Listeria monocytogenes Serogroup IIa Isolated in Poland
}

\author{
Beata Lachtara (D), Kinga Wieczorek (D) and Jacek Osek *(D) \\ Department of Hygiene of Food of Animal Origin, National Veterinary Research Institute, 24-100 Pulawy, Poland; \\ beata.lachtara@piwet.pulawy.pl (B.L.); kinga.wieczorek@piwet.pulawy.pl (K.W.) \\ * Correspondence: josek@piwet.pulawy.pl
}

Citation: Lachtara, B.; Wieczorek, K.; Osek, J. Genetic Diversity and Relationships of Listeria monocytogenes Serogroup IIa Isolated in Poland. Microorganisms 2022, 10, 532. https://doi.org/10.3390/ microorganisms10030532

Academic Editors: Ana Botelho and Mónica Oleastro

Received: 11 February 2022 Accepted: 25 February 2022 Published: 28 February 2022

Publisher's Note: MDPI stays neutral with regard to jurisdictional claims in published maps and institutional affiliations.

Copyright: (C) 2022 by the authors. Licensee MDPI, Basel, Switzerland. This article is an open access article distributed under the terms and conditions of the Creative Commons Attribution (CC BY) license (https:// creativecommons.org/licenses/by/ $4.0 /)$.

\begin{abstract}
In the present study, 100 L. monocytogenes isolates of serogroup IIa from food and food production environments in Poland were characterized towards the presence of virulence, resistance, and stress response genes using whole-genome sequencing (WGS). The strains were also molecularly typed and compared with multi-locus sequence typing (MLST) and core genome MLST analyses. The present isolates were grouped into 6 sublineages (SLs), with the most prevalent SL155 (33 isolates), SL121 (32 isolates), and SL8 (28 isolates) and classified into six clonal complexes, with the most prevalent CC155 (33 strains), CC121 (32 isolates), and CC8 (28 strains). Furthermore, the strains were grouped to eight sequence types, with the most prevalent ST155 (33 strains), ST121 (30 isolates), and ST8 (28; strains) followed by 60 cgMLST types (CTs). WGS data showed the presence of several virulence genes or putative molecular markers playing a role in pathogenesis of listeriosis and involved in survival of L. monocytogenes in adverse environmental conditions. Some of the present strains were molecularly closely related to L. monocytogenes previously isolated in Poland. The results of the study showed that food and food production environments may be a source of L. monocytogenes of serogroup IIa with pathogenic potential.
\end{abstract}

Keywords: Listeria monocytogenes; WGS; serogroup IIa; food; molecular typing

\section{Introduction}

Listeria monocytogenes is responsible for a foodborne disease in humans called listeriosis, which is characterized by a high mortality rate [1-4]. According to the recent European Food Safety Authority (EFSA) and European Centre for Disease Prevention and Control (ECDC) report, in 2020, a total of 1876 confirmed listeriosis cases in humans in the European Union, with the notification rate of 0.42 per 100,000 population, were noted [5]. Among them, 62 infections ( 0.16 notification rate) were identified in Poland.

L. monocytogenes is widespread in the environment, including food production areas, and many different kinds of foods were linked to human infection [6,7].

L. monocytogenes is classified into four evolutionary lines (I, II, III, and IV) and four molecular serogroups (IIa, IIc, IIb, and IVb), which cover different serotypes $(1 / 2 \mathrm{a}, 3 \mathrm{a}$, $1 / 2 c, 3 c, 1 / 2 b, 3 b, 4 b, 4 d$, and 4e) [8-10]. Several studies have indicated strains divergence regarding their ability to persist in the environment as well as their virulence potential [10]. It has been shown that among isolates classified into the evolutionary line II, there are L. monocytogenes of serogroup IIa, which are often over-represented in food and food processing environments; such isolates are usually characterized by a high prevalence of various virulence marker genes and are often identified in humans with listeriosis [11-14].

Recent application of whole-genome sequencing (WGS) into bacterial molecular characterization provides much data on the relationship of L. monocytogenes from different sources and allows the classification of the strains into evolutionary lines and genetic types [15-17]. Based on the WGS, the multilocus sequence typing (MLST) approach allows classification of L. monocytogenes into clonal complexes (CCs) and sequence types (STs), 
which are linked with persistence of the strains in food, food production environments or with a high potential to cause listeriosis [18-21]. It has been shown that L. monocytogenes of CC121 classified as serogroup IIa has been often isolated from different food processing plants for several years, which makes them serious problems for the food industry and poses a potential threat for consumers [20]. Other data also suggest that L. monocytogenes IIa serogroup, classified to CC8, CC155, and other clonal complexes, have persistent properties and have been identified in different niches or sources $[15,17,18]$. WGS data also provides an opportunity to characterize L. monocytogenes based on the core genome multilocus sequence typing (cgMLST) that allows a standardized comparison of the sequences of the tested strains with the publicly available genomes present in databases [11,22,23].

The WGS analysis also delivers information related to the virulence properties and potential of L. monocytogenes to survive under a wide range of suboptimal environmental conditions. One of such markers is Premature Stop Codon Mutations (PMSC) in the inlA gene responsible for the production of internalin A, which mediates bacterial adhesion and invasion of epithelial cells in the human intestine [24]. Strains with such truncated genes are rarely involved in human listeriosis infections but more often are detected among food isolates [25]. There are also reports showing that persistent isolates from food processing plants and ecosystems exhibited higher resistance to quaternary ammonium compounds (QACs) than non-persistent ones, especially strains classified to IIa serogroup [26,27]. Furthermore, QAC-tolerant $L$. monocytogenes have a higher ability to form protective biofilms and are characterized by an increased tolerance to other types of QAC-based biocides used in the food industry [28].

The aims of the present study were: (i) to characterize the virulence potential and assess the genetic diversity of L. monocytogenes serogroup IIa isolated in Poland using WGS analysis; (ii) to determine the molecular relationships of isolates tested; and (iii) to compare the present $L$. monocytogenes with the sequences of other isolates of IIa serogroup isolated previously in Poland available in BIGSdb-Lm database.

\section{Materials and Methods}

\subsection{Sample Collection}

A total of 1439 L. monocytogenes isolates were obtained during routine food and food production environments microbiological investigations performed by official veterinary laboratories located in 13 out of 16 administrative regions (voivodeships) of Poland during 2013-2019 using the ISO-11290-1 standard [29]. The isolates were then sent to the National Veterinary Research Institute, National Reference Laboratory for L. monocytogenes in Pulawy and tested towards molecular serogroups with PCR as described $[8,30]$. For the present study, 100 L. monocytogenes isolates classified to serogroup IIa and recovered from raw meat $(n=19)$, ready-to-eat (RTE) food of animal origin $(n=48)$, and from food production environments (FPEs) $(n=33)$ were selected and stored in Viabank (Medical Wire and Equipment, Corsham, Wiltshire, UK) at $-80{ }^{\circ} \mathrm{C}$. Detailed information on the L. monocytogenes isolates used is shown in Table S1.

\subsection{DNA Isolation and Sequencing}

L. monocytogenes was cultured on tryptone soya-yeast extract agar at $37^{\circ} \mathrm{C}$ for $18-24 \mathrm{~h}$ and a loopful of bacteria was transferred into $100 \mu \mathrm{L}$ of TRIS (Tris-(hydroxymethyl)aminomethane) buffer (A\&A Biotechnology, Gdynia, Poland). DNA was extracted using the Genomic Mini protocol (A\&A Biotechnology) modified by adding $20 \mu \mathrm{L}$ of lysozyme $\left(10 \mathrm{mg} / \mathrm{mL}\right.$; Sigma-Aldrich, St. Louis, MO, USA) and incubation of the samples at $37^{\circ} \mathrm{C}$ for $30 \mathrm{~min}$.

DNA quality and concentration were measured by NanoDrop or Qubit 3 (Thermo Fisher Scientific, Waltham, MA, USA), and sequencing libraries were prepared with a Nextera XT DNA Sample Preparation Kit (Illumina, San Diego, CA, USA) and a KAPA HyperPlus Kit (Hoffman-La Roche, Basel, Switzerland) according to the manufacturer's instruction. The libraries were then sequenced in a MiSeq (Illumina) and NextSeq (Illumina) 
with approximately $50 \times$ and $100 \times$ average coverage. The sequences were trimmed using Trimmomatic v.0.36 [31] and Fastp v.0.22.0 and finally assembled wit SPAdes v.3.9.0 and v.3.15.3 [32].

The detailed L. monocytogenes sequence parameters used in the present study are listed in Table S2. All genome sequences obtained were deposited in the Listeria PasteurMLST database (https:/ / bigsdb.pasteur.fr/listeria (accessed on 15 January 2022)) under the accession numbers 79375-79474.

\subsection{WGS Analysis}

All L. monocytogenes sequences were analyzed using the publicly available web-based WGS tools on the BIGSdb-Lm platform (https://bigsdb.pasteur.fr/listeria (accessed on 15 January 2022)) [11,22,33].

MLST profiles with the same alleles for 7 loci were classified into sequence types (ST) and grouped into clonal complexes (CCs) if at least 5 out of 7 loci were the same as previously described [11,34]. cgMLST (1748 loci) profiles were grouped into cgMLST types (CTs) and sublineages (SLs), using the cut-offs of 7 and 150 allelic mismatches, respectively, as previously described [11]. Minimum spanning tree (MST) was generated using BioNumerics software version 7.6 (Applied Maths, Sint-Martens-Latem, Belgium) based on the cgMLST allele number and the predefined template for categorical data.

Assemblies were also screened in silico for virulence factor, antimicrobial, metal, and biocide resistance genes, Listeria Stress Islands as well as the $\operatorname{sig} B$ and rhamnose operons using the BIGSdb-Lm platform [11,19,35-38]. The obtained sequences were further analyzed for the presence of $q a c H$ and emrC gene using BLAST (https://blast.ncbi.nlm. nih.gov/Blast.cgi (accessed on 20 January 2022)) and the reference sequences described before $[39,40]$.

The putative prophage determinants within the genomes of the L. monocytogenes isolates were identified using the PHASTER (PHAge Search Tool Enhanced Release) web server [41,42]. To identify the presence of plasmid sequences the WGS sequences were analyzed with PlasmidFinder software 2.1 for the specified Gram-positive scheme (https: / / cge.cbs.dtu.dk/services / PlasmidFinder (accessed on 18 January 2022)) [43].

\subsection{Comparison of L. monocytogenes Sequences}

The WGS sequences of the isolates tested in the present study were compared with 39 sequences of Polish L. monocytogenes publicly available in BIGSdb-Lm database. Isolates classified to CC8, CC121, and CC155, recovered from humans, food, and food production environments were selected. The cgMLST profiles of all compared strains were created using sequences of the 1748 loci according to the scheme described before [11]. The minimum spanning trees (MSTs) based on cgMLST profiles were constructed using the BioNumerics 7.6 software as previously described [30]. The strains were classified to the same cluster when less than 7 allelic differences were identified. Phylogenetic tree was constructed using BioNumerics 7.6 based on cluster analysis (similarity matrix) of the categorical differences in the allelic cgMLST profiles for each isolate using the single linkage calculating method. Detailed information on the L. monocytogenes isolates used for comparisons are listed in Table S3.

\section{Results and Discussion}

\subsection{WGS-Based Typing of L. monocytogenes of IIa Serogroup}

Analysis of WGS data of the 100 L. monocytogenes isolates allowed to classify them into 6 clonal complexes (Figure 1). Three main CCs identified covered the vast majority of the isolates, i.e., CC155 (33; 33.5\%), CC121 (32; 32.0\%), and CC8 (28; 28.0\%), and they were originated from all sources tested. The remaining seven strains, mainly recovered from RTE food, were grouped into three CCs, with single isolates in each (Figure 1). L. monocytogenes of the CCs identified in the present study were also previously detected among 100 strains 
of IIa serogroup recovered from food but were also often isolated from humans with listeriosis [12,14,18,44-47].

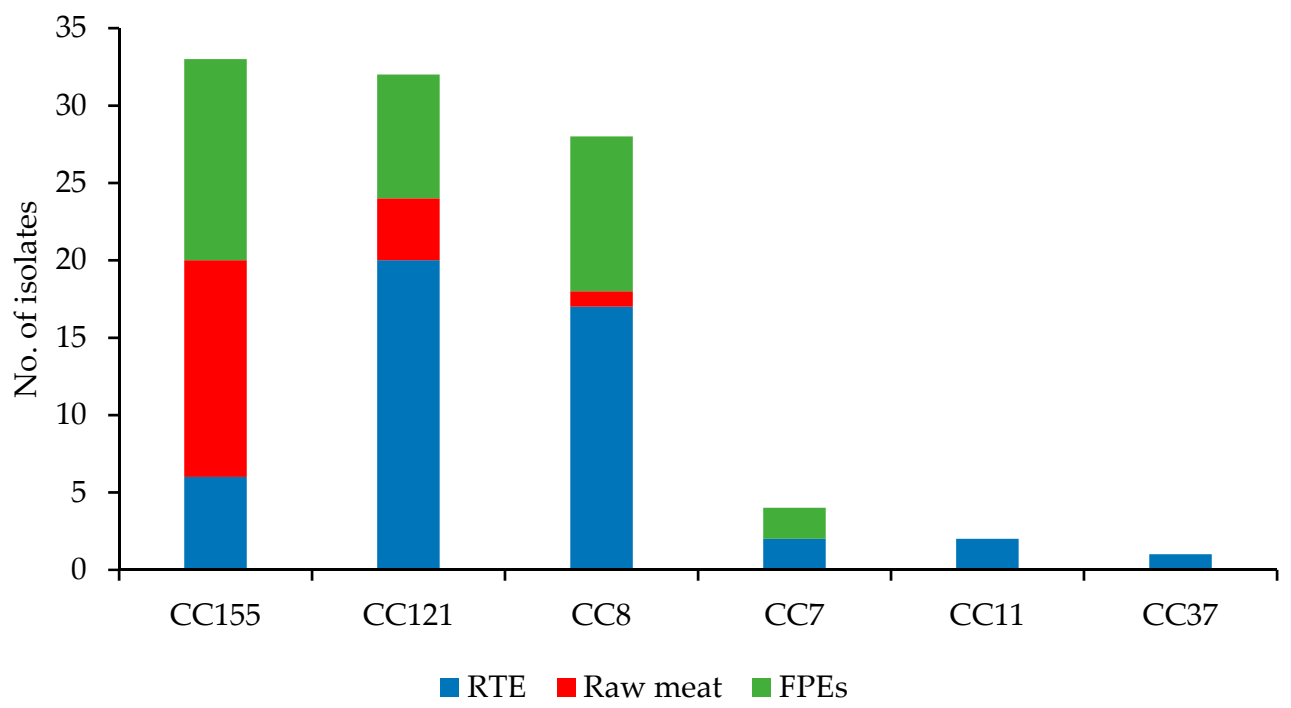

Figure 1. Distribution of clonal complexes (CCs) among of 100 L. monocytogenes isolates tested (RTE, ready-to-eat meat; FPEs, food production environments).

Further analysis of WGS sequences revealed that all 100 current isolates were classified into eight sequence types, with the most prevalent ST155 (33; 33.0\%), ST121 (30; 30.0\%), and ST8 $(28 ; 28.0 \%$ ) (Figure 2). The remaining nine strains belonged to five distinct STs (ST7, ST12, ST37, ST451, and ST1398) and were mainly isolated from RTE food. The number of STs in relation to different sources of the strains tested is shown in Table 1. Three STs (ST8, ST121, and ST155) were identified in L. monocytogenes isolated from all three sources analyzed (Table 1). The results of other authors also showed that ST155 and ST121 were often identified among L. monocytogenes of food origin [14,15,21]. It seems that such isolates may have a molecular background that allows them to survive in food and food production environments in different areas for a long time [11,15].

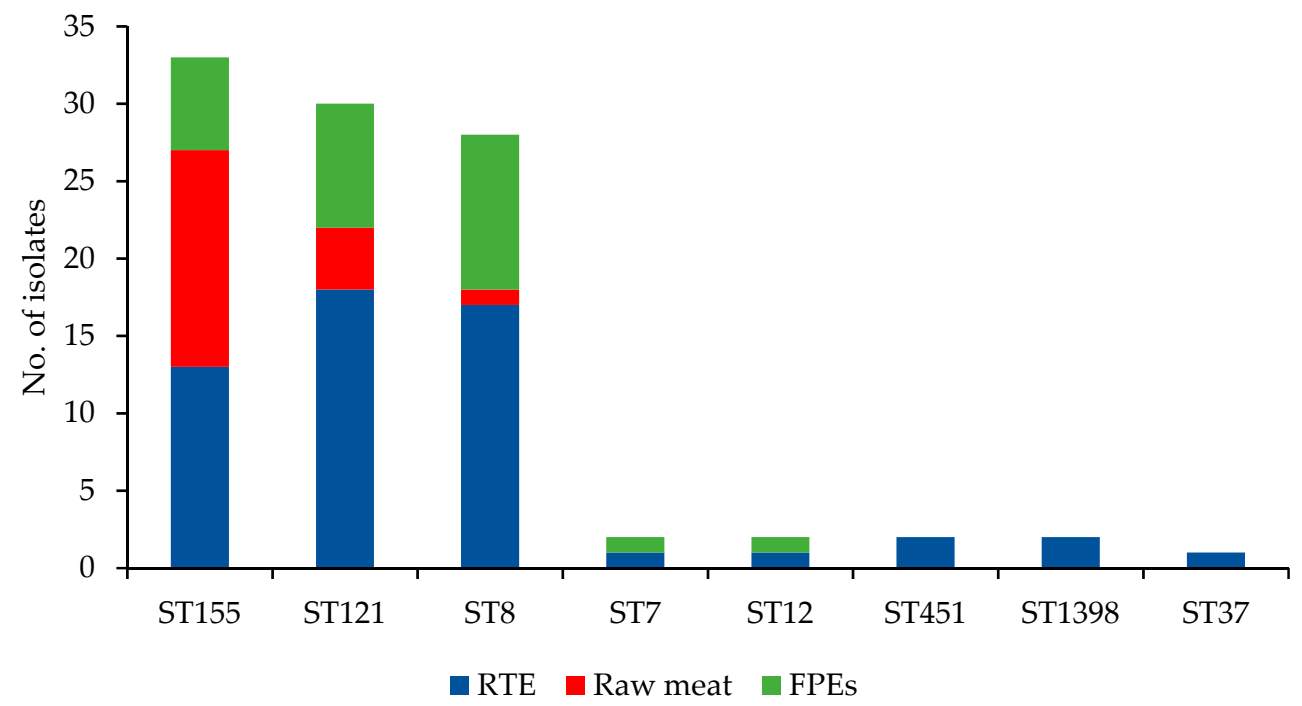

Figure 2. Distribution of sequences types (STs) among of 100 L. monocytogenes isolates tested (RTE, ready-to-eat meat; FPEs, food production environments). 
Table 1. Prevalence of sequence (ST) and cgMLST (CT) types among L. monocytogenes tested.

\begin{tabular}{ccccccccc}
\hline \multirow{2}{*}{ Source of Isolates } & \multicolumn{2}{c}{ No. of Total Types } & \multicolumn{2}{c}{$\begin{array}{c}\text { Most Common Types } \\
\text { (No. of Isolates) }\end{array}$} & \multicolumn{2}{c}{$\begin{array}{c}\text { No. of Types Unique } \\
\text { for the Source }\end{array}$} & \multicolumn{2}{c}{ Common to All Sources } \\
\cline { 2 - 9 } & ST & CT & ST & CT & ST & CT & ST & CT \\
\hline Raw meat $(n=19)$ & 3 & 10 & ST155 (14) & CT1170 (6) & 0 & 6 & ST8; & CT750; \\
RTE food $(n=48)^{a}$ & 8 & 36 & ST121 (18) & CT1170 (6) & 3 & 31 & ST121; & CT1170 \\
FPEs $(n=33)^{\mathrm{b}}$ & 5 & 22 & ST155 (13) & CT9831 (6) & 0 & 17 & ST155 \\
\hline
\end{tabular}

${ }^{a}$ RTE, ready-to-eat. ${ }^{b}$ FPEs, food production environments.

Based on the WGS sequences, the present isolates were grouped into 6 sublineages (SLs), with the most prevalent SL155 (33 isolates), SL121 (32 isolates), and SL8 (28 isolates) (Table S1). During the investigation of Hurley et al. (2019), some of their 100 L. monocytogenes strains were classified to the same sublineages as identified in the present study: SL121 (12\% isolates), SL8 (10\%), SL7 (8\%), SL451 (4\%), and SL37 (1\%). Our previous analysis of $48 \mathrm{~L}$. monocytogenes isolates originated from food and food processing environments in Poland showed 25 different CTs grouped into seven SLs, but none of those strains was classified into the same sublineages as identified in the current study. However, those isolates were classified to other serogroups [48].

The present isolates were further grouped into 60 different cgMLST types (CTs), with the most numerous CT1170 (17 isolates) and CT750 (12 strains), both mainly recovered from RTE food and food production environments (a total of 12 and 11 isolates, respectively), but also from raw meat (five isolates of CT1170) (Figure 3). There were also CTs unique to the source of isolation (Table S1). The number of CTs identified in the strains of different origins tested is shown in Table 1.

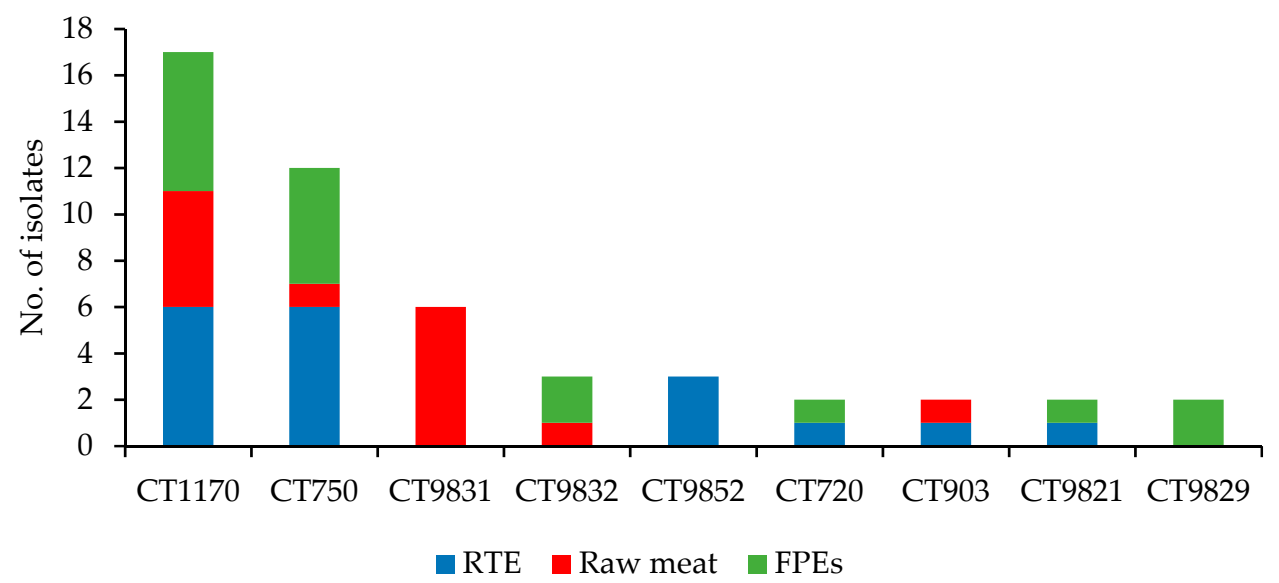

Figure 3. Distribution of cgMLST types (CTs) among of 100 L. monocytogenes isolates tested, which were identified in more than one isolate.

A similar study performed by Hurley et al. (2019) showed a large molecular diversity among 100 L. monocytogenes isolates from food and food processing environments in Ireland. These authors identified a total of 37 distinct cgMLST types, with the most abundant being CT1526 (20 strains), followed by CT1844 (11 isolates) and CT1828 (7 strains). However, none of these CTs was detected in the current investigation.

\subsection{General Molecular Characteristics of L. monocytogenes}

Several genetic molecular markers involved in the pathogenesis of L. monocytogenes infection and survival of the bacteria in adverse environmental conditions were identified from the WGS data of 100 isolates tested (Table S1). One of these important genes are four Listeria Pathogenicity Islands (LIPIs). Among them, LIPI-1 are essential for invasion, intracellular growth, and further spread to adjacent cells during the listeriosis infectious 
cycle [49]. The LIPI-1 island was identified in all isolates tested in the present study, irrespective of their clonal complex (Table S1). It has been previously shown that this gene is present in all L. monocytogenes and is composed of six genes, including $\operatorname{prf} A$, act $A, h l y, m p l$, iap, $p l c A$, and $p l c B$ (Table 2) [50]. On the other hand, none of the L. monocytogenes harbored other LIPI virulence islands, i.e., LIPI-2 involved in the expression of invasion-associated surface proteins, LIPI- 3 with the $l l s X$ gene responsible for the production of listeriosin $S$ (LLS toxin), which promotes post-translational modifications, and LIPI-4, a cluster of six genes and is involved in neural and placental infection [33,51]. The lack of these genes may suggest that the currently tested isolates had a low pathogenic potential for humans.

Table 2. Distribution of virulence and resistance factor genes among L. monocytogenes isolates tested in relation to the clonal complexes (CCs) and sequence types (STs).

\begin{tabular}{|c|c|c|c|c|c|}
\hline \multirow{3}{*}{ Trait } & \multirow{3}{*}{ Gene } & \multicolumn{4}{|c|}{ No. of Isolates } \\
\hline & & \multirow{2}{*}{$\begin{array}{l}\mathrm{CC155}(n=33) \\
\mathrm{ST} 155(n=33)\end{array}$} & \multicolumn{2}{|c|}{ CC121 $(n=32)$} & \multirow{2}{*}{$\begin{array}{l}\text { CC8 }(n=28) \\
\text { ST8 }(n=28)\end{array}$} \\
\hline & & & ST121 $(n=30)$ & ST1398 $(n=2)$ & \\
\hline \multirow{4}{*}{$\begin{array}{l}\text { Metal \& disinfectants } \\
\text { resistance }\end{array}$} & $b c r A$ & 12 & 0 & 0 & 0 \\
\hline & $b c r B$ & 12 & 0 & 0 & 0 \\
\hline & $b c r C$ & 12 & 0 & 0 & 0 \\
\hline & ermC (Tn6118_qac) & 0 & 13 & 0 & 2 \\
\hline \multirow{7}{*}{ Stress Islands } & SSI1_lmo0444 & 33 & 0 & 0 & 27 \\
\hline & SSI1_lmo0445 & 33 & 0 & 0 & 28 \\
\hline & SSI1_lmo0446 & 33 & 0 & 0 & 28 \\
\hline & SSI1_lmo0447 & 33 & 0 & 0 & 28 \\
\hline & SSI1_lmo0448 & 32 & 0 & 0 & 28 \\
\hline & SSI2_lin0464 & 0 & 30 & 2 & 0 \\
\hline & SSI2_lin0465 & 0 & 30 & 2 & 0 \\
\hline \multirow{9}{*}{ Internalins } & inlA & 33 & 29 & 2 & 27 \\
\hline & inlB & 33 & 30 & 2 & 28 \\
\hline & inlc & 33 & 30 & 2 & 28 \\
\hline & inlE & 33 & 30 & 2 & 28 \\
\hline & $i n l F$ & 33 & 0 & 0 & 28 \\
\hline & $i n l G$ & 33 & 0 & 0 & 28 \\
\hline & $i n l H$ & 33 & 30 & 2 & 28 \\
\hline & inlJ & 33 & 30 & 2 & 27 \\
\hline & $i n l K$ & 33 & 30 & 2 & 27 \\
\hline \multirow{6}{*}{ LIPI-1 } & $\operatorname{prfA}$ & 33 & 30 & 2 & 28 \\
\hline & plcA & 33 & 27 & 2 & 28 \\
\hline & hly & 33 & 30 & 2 & 28 \\
\hline & $m p l$ & 33 & 29 & 2 & 27 \\
\hline & $\operatorname{act} A$ & 33 & 30 & 2 & 28 \\
\hline & $p l c B$ & 33 & 30 & 2 & 26 \\
\hline
\end{tabular}

Other important genes playing a possible role in the persistence of L. monocytogenes in food production environments, such as sequences encoding resistance to cadmium, e.g., the cadA1 gene located on plasmid-borne Tn5422 transposon and a metal-responsive transcriptional repressor $\mathrm{cadC}$, previously identified, e.g., among isolates of CC155 [52], were not detected in any of the strains tested, including those belonging to CC155 (Table S1). This result is opposite to the study of Wagner et al. (2020), who showed that the vast majority of their L. monocytogenes CC155 isolates tested these cadmium resistance markers. Another investigation demonstrated that the cadA1 gene was identified mainly in strains of serotypes $1 / 2 \mathrm{a}$ and $1 / 2 \mathrm{~b}$ originated from food and food-processing environment [53,54]. In the present study, all L. monocytogenes tested were classified to serogroup IIa, which covers serotype $1 / 2 \mathrm{a}$, but all isolates were negative for this sequence.

The WGS data were also analyzed towards the presence of sigma factor protein (sigB) operon, responsible for the adaptation of L. monocytogenes to several stress conditions, which 
may be present in food production environments, such as low temperatures, $\mathrm{pH}$, high hydrostatic pressure, and biofilm formation $[55,56]$. It was shown that the $\operatorname{sig} B$ operon was present in all currently investigated strains (Table S1), and similar results were previously described by other authors $[14,21,57]$.

Analysis of WGS sequences of 100 L. monocytogenes isolates tested showed the presence of several mobile genetic elements such as plasmids (Table S4). Among them, the most common was plasmid pLM5578 identified only among all 32 strains classified to CC121. It has been previously shown that this plasmid contains sequences encoding resistance to cadmium ( $c a d A$ and $c a d C$ ), which play a role in the survival of such isolated in adverse food processing environments and increase their pathogenic potential $[35,58,59]$. However, none of the current strains tested with plasmid pLM5578 was positive for the cadA and cadC sequences (Table S1).

Other genetic elements which potentially enhance the survival, virulence, or fitness of $L$. monocytogenes are prophages $[21,60]$. The present investigation revealed the presence of 11 different intact prophage sequences detected among 64 of 100 isolates tested, with the most common PHAGE_Lister_LP_HM00113468_NC_049900 sequence found in 20 strains, mostly of CC8 (Table S4). Another frequently identified phage sequence was PHAGE_Lister_LP_101_NC_024387 (18 isolates), which was detected among strains classified into five CCs, mainly to CC121 (10 isolates) (Table S4). Previous studies also showed that $L$. monocytogenes originated from humans with listeriosis but also from food and food production environments from different countries had various prophage sequences inserted into the genome, including those identified in the present study [59,61-63]. It may suggest that the phage sequences presently detected are commonly found among L. monocytogenes identified all over the world. However, their exact role in survival, persistence, and virulence has to be further evaluated $[60,64,65]$.

The remaining virulence, resistance, stress response, and other genes identified in $100 \mathrm{~L}$. monocytogenes isolates tested are discussed in paragraphs related to particular clonal complexes and shown in Table 2, Tables S1 and S4. Additionally, the phylogenetic tree based on cgMLST profiles with the presence/absence of the most important genes of interest as well as additional information about all isolates tested is shown in Figure S1.

\subsection{Molecular Characteristics of L. monocytogenes of Different CCS}

\subsubsection{CC155 Isolates}

L. monocytogenes of the most prevalent clonal complex $(\mathrm{CC} 155 ; n=33)$ harbored only isolates classified into one MLST sequence type ST155 and nine different cgMLST types, with the most prevalent CT1170 (17; 51.5\% isolates) followed by CT9831 $(6 ; 18.2 \%)$ (Table S1). Strains of CC155 were mainly recovered from raw meat $(14 ; 42.4 \%$ isolates) and FPEs (13;39.4\%). As described by Wagner et al. (2020) L. monocytogenes of CC155 are often identified in food and food production environments as well as among clinical isolates due to their genetic attributes supporting their ability to persist in environments as well as to infect humans. One of these features, especially important in surviving under adverse environmental conditions, is resistance to quaternary ammonium compounds (QAC) such as benzalkonium chloride (BC), which depends on the presence of efflux pump genes, such as $b c r A B C$ cassette [66]. In the present study, 12 out of 33 (36.4\%) L. monocytogenes of CC155 were positive for this marker. The isolates were mainly from raw meat (7 isolates) and food production environments ( 4 strains) (Table S1). Furthermore, none of the strains possessed the qacA gene, which is also involved in BC resistance [66]. A study by Wagner et al. (2020) showed that all but one of $20 \mathrm{~L}$. monocytogenes classified to CC155, isolated from food and clinical sources, were positive for the $b c r A B C$ cassette. Since, in most cases, the qac $A$ gene is located on the pLM80 plasmid, it can be easily lost or transferred between diverse L. monocytogenes of various sources [58,67].

Further analysis of WGS sequences of L. monocytogenes CC155 tested revealed that none of them was positive for the chromosomally located Tn6188_qac (ermC) transposon harboring the qacH efflux pump gene involved in tolerance to BC and other QACs [68]. 
Similar observations were made by Wagner et al. (2020), who showed that none of their strains tested possessed this marker. On the other hand, a study by Meier et al. (2017) demonstrated that the majority of Swiss and Finnish L. monocytogenes clinical and food isolates resistant to BC were qacH-positive [26].

A correlation between the ability to biofilm formation by different $L$. monocytogenes strains and the presence of stress survival islet 1 (SSI-1) was previously demonstrated [69]. Genomic analysis of the current isolates classified into CC155 showed that all of them were positive for this marker (Table 2). It has been previously described that such SSI-1 positive L. monocytogenes are able to form stronger biofilm structures compared to SSI-1 negative strains. Thus, they show better persistent properties, which allow them to survive in food production environments for a long time [70,71].

Another important marker involved in biofilm formation is the inlA gene responsible for the expression of internalin A [72]. It has been demonstrated that L. monocytogenes carrying the PMSC mutation in the inlA gene, which results in the reduced length of InlA protein, showed enhanced biofilm-forming abilities but decreased virulence compared to the isolates that had full-length InlA [25]. Furthermore, such mutation occurs more commonly among food isolates than in strains responsible for human infections [73]. In the current investigation, none of the CC155 L. monocytogenes tested possessed the truncated inlA internalin gene, which may suggest their increased pathogenic potential for humans (Table S1).

\subsubsection{CC121 Isolates}

L. monocytogenes classified to clonal complex CC121 $(n=32)$ belonged to two STs: ST121 (30 isolates) and ST1398 (2 strains), among them, a total of 28 different cgMLST types were identified (Table S1). The majority of the CC121 isolates were originated from RTE food (20; $62.5 \%$ strains). The remaining isolates were either from food production environments $(8 ; 25.0 \%)$ or raw meat $(4 ; 12.5 \%)$. L. monocytogenes classified to sequence type ST121 seems to be very well adapted to conditions present in food production environments and was isolated during several studies related to food production $[59,74,75]$. Furthermore, such isolates have been identified in any of the hypo-virulent clones but are sometimes associated with human listeriosis $[26,59,76]$.

Screening of the WGS data towards pathogenic markers among L. monocytogenes CC121 revealed that the $b c r A B C$ and qacA genes connected with resistance to $B C$ were not identified in any of the 32 strains (Table S2). These results are opposite to other studies where such BC tolerance gene markers were present, at least in some strains of clonal complex 121 [26,77].

Further analysis of the WGS data was performed towards another efflux pump gene responsible for the increased tolerance of L. monocytogenes to QAC, i.e., Tn6188_qac (ermC) transposon with the qacH efflux pump gene connected with pLMST6 plasmid [78]. It was found that this transposon was present in 13 (40.6\%) strains of CC121 (Table 2). This BC resistance sequence was also often identified during other studies on $L$. monocytogenes isolated from food or food production environments [26,71]. However, there are also studies that demonstrated that this efflux pump determinant was not identified in any of L. monocytogenes isolates of food and human origin; however, these strains were classified into ST155 type [21].

The investigation of the presence of stress survival islet 1 (SSI-1), one of the gene markers involved in biofilm formation and persistence of L. monocytogenes showed that, in contrast to strains of CC155, all CC121 isolates tested were negative for this sequence (Table 2). This may suggest that the CC121 L. monocytogenes tested do not have strong properties responsible for the survival of the bacteria in adverse food production environment conditions $[70,71]$. However, the current CC121 isolates were positive for stress survival islet 2 (SSI-2) involved in the survival of L. monocytogenes under alkaline and oxidative stress conditions [36]. 
Analysis of the present WGS data towards the inlA internalin trait, another gene involved in biofilm development by L. monocytogenes, including the PMSC sequence mutation, revealed that all but one isolates of CC121 tested carried the truncated gene (Table S1), which resulted in the reduced length of InlA protein and had an influence on enhanced biofilmforming abilities [25]. This finally makes such isolates being well adapted for survival and persistence in the environment present in food production environments $[15,25,77]$. On the other hand, such isolates may be less pathogenic for humans [73].

\subsubsection{CC8 Isolates}

All 28 L. monocytogenes isolates tested classified into clonal complex CC8 belonged to one sequence type (ST8) and 17 different cgMLST types, with the most predominant CT750 (12; $42.9 \%$ isolates) (Table S1). All but one strain were recovered from RTE food (17; $60.7 \%$ ) and food production environments $(10 ; 35.7 \%)$. L. monocytogenes of ST8, such as the characterized above ST121, was previously often isolated from food and food production areas, which suggests that strains of such sequence type can survive in adverse conditions present in such environments $[13,74,77,79,80]$. Furthermore, such isolates have probably increased virulence properties since they were also responsible for human listeriosis cases $[47,59,81,82]$.

WGS data analysis of CC8 strains towards virulence and resistance markers showed that the main genes responsible for resistance to benzalkonium chloride, i.e., $b c r A B C$ and $q a c A$, were not present in any of the 28 isolates tested. This result is identical to the current L. monocytogenes classified to CC121. Only two CC8 isolates of cgMLST types CT750 and CT9837, both of food production environments origin, were positive for the Tn6188_qac $(\mathrm{ermC})$ transposon involved in QAC and other various disinfectants resistance widely used in food production (Table 2) [68,71]. Isolates belonging to CC 8 were also previously identified in food and in humans suffering from listeriosis $[18,26,45-47,83]$. However, there are also studies in which none of the L. monocytogenes classified to CC 8 was positive for the Tn6188_qac (ermC) marker [49,80].

The ability of biofilm formation, another important characteristic of persistent L. monocytogenes isolates responsible for food contamination, depends on several molecular markers such as stress survival islet 1 (SSI-1) and inlA. The analysis of WGS sequences of CC 8 strains tested revealed that the SSI-1 gene was present in all isolates (Table 2). Previous studies suggested serotype-specific differences in biofilm development linked to the presence of SSI-1 $[69,84,85]$. Additionally, all but one isolates of CC8 were positive for the full length of the inlA (internalin) gene (Table S1). This may indicate that such strains demonstrated weaker biofilm-forming abilities but enhanced virulence compared to the isolates that had PMSC mutation in this sequence as currently identified in L. monocytogenes classified to CC121 (Table S2) [25].

\subsubsection{Isolates of the Remaining CCs}

A total of seven remaining L. monocytogenes isolates tested were classified to CC7 (4 strains), CC11 (2 isolates), and CC37 (one strain). They were recovered from RTE food or food production environments and characterized towards sequence and cgMLST types (Table S1). The isolates showed a high molecular diversity belonging to four STs (ST7; ST12, ST37, and ST451) and six CTs (CT720; CT798; CT4399; CT9808; CT9849; CT9850). L. monocytogenes of such clonal complexes were previously isolated from food, although their prevalence was rather low $[86,87]$.

Analysis of the WGS sequences towards the main genes responsible for resistance to biocides such as benzalkonium chloride, i.e., $b c r A B C$ and $q a c A$, revealed that none of these markers was identified (Table S2). Furthermore, all strains were negative for the Tn6188_qac (ermC) transposon involved in QAC and other disinfectants resistance used in food production [68].

All these seven L. monocytogenes tested did not possess sequences encoding resistance to cadmium (cadA1 gene). However, the stress survival islet 1 (SSI-1) involved in biofilm 
formation was present in four isolates classified to ST7 and ST12 (two strains of each), whereas another biofilm-related marker (inlA gene) was found in all isolates, but it was without the PMSC mutation suggesting their weaker biofilm-forming ability [25].

\subsection{Molecular Relationships of the Current and Other Polish L. monocytogenes}

L. monocytogenes of CC155 were grouped into six clusters covering from two to nine isolates (Figure S2). The most numerous group of L. monocytogenes consisting of isolates classified to the same cgMLST type (CT1170; $n=17)$ was separated into three distinct clusters and were obtained from eight different voivodeships during years 2014-2019 (Figure S1A-C). Among one cluster with a total of nine out of 17 CT1170 isolates, there were strains obtained during years 2014-2018 in seven voivodeships and were mainly originated from RTE meat (Table S1). The remaining eight CT1170 L. monocytogenes isolates were classified into two clusters and were originated from wielkopolskie (five strains) and warmińsko-mazurskie (three strains) voivodeships, respectively, and were recovered from 2017 to 2019 (Figure S1B,C).

Furthermore, among CC155 isolates, there were two clusters with the molecularly identical strains classified into the same cgMLST types: CT9831 (six isolates, all of raw meat origin), identified in the same voivodeship (mazowieckie) during years 2013-2014 (Figure S2D) and CT9832 (three isolates from two voivodeships; Figure S2E), respectively. The other two strains of CC155 belonged to CT9829 and were isolated from FPEs in two voivodeships in 2015 and 2018 (Figure S2F).

Molecular relationship of the current L. monocytogenes isolates classified into CC155, based on the cgMLST analysis, are shown in Figure 4. They were also compared with six other strains of the same clonal complex previously identified in Poland. MST analysis showed a close relationship of one isolate (ID79401) of CT1170, originated from food, with the strain of ID46913 also isolated from food (only five allelic differences). Other Polish L. monocytogenes sequences available in BIGSdb-Lm database were not closely related to the isolates investigated during the present study (Figure 4).

Comparative analysis of L. monocytogenes strains belonging to CC121 and showing over 95\% similarity based on the cgMLST data revealed three clusters with two or three strains in each, classified into three different CTs (Figure S3). The strains were either isolated from the same voivodeship (łódzkie; three isolates of CT9852 from 2013 of RTE meat origin; Figure S3A or kujawsko-pomorskie, two isolates of CT9821, from 2015 from RTE and 2016 from FPEs, Figure S3B) or from different voivodeships (łódzkie i podkarpackie, both strains of CT903 from 2014 from RTE and 2015 from raw meat, Figure S3C).

Molecular relationship of the current L. monocytogenes isolates classified into CC121, based on the cgMLST analysis, are shown in Figure 5. They were also compared with 19 other strains of the same clonal complex previously identified in Poland. The analysis revealed that only one presently tested strain (ID79402, classified to CT1249 and isolated from food production environments in kujawsko-pomorskie voivodeship in 2015) showed a close relationship (three allelic differences) with two strains (ID46896 and ID46897) originated from the same source in 2019. The remaining 31 current L. monocytogenes CC121 isolates have not displayed a close relationship with previously isolated strains identified in our country, i.e., showed more than seven allelic differences (Figure 5).

Analysis of molecular similarity of strains classified to CC8 revealed that the most predominant L. monocytogenes of CT750 (12 isolates) were grouped into four clusters containing from four to two identical or closely related isolates (Figure S4). For example, isolate ID79412 recovered in 2016 from food production environments in małopolskie voivodeship displayed from three to four allelic differences with two other isolates (ID79386 and ID79389) recovered from two voivodeships (łódzkie in 2014 and podkarpackie in 2015), and both strains were of RTE meat origin (Figure S4A). Strains with ID79449 and ID79408, also recovered from food production environments but in different voivodeships and during different years (Figure S4B), were also closely related as tested by the cgMLST profiles (five alleles mismatches; Figure 6). Furthermore, strain ID79412 was very similar to 
L. monocytogenes ID34379 isolated in Poland in 2012 from a person with listeriosis. However, the remaining sequences of 11 historical Polish strains did not show a close molecular relationship with the current isolates belonging to CC8 (Figure 6).

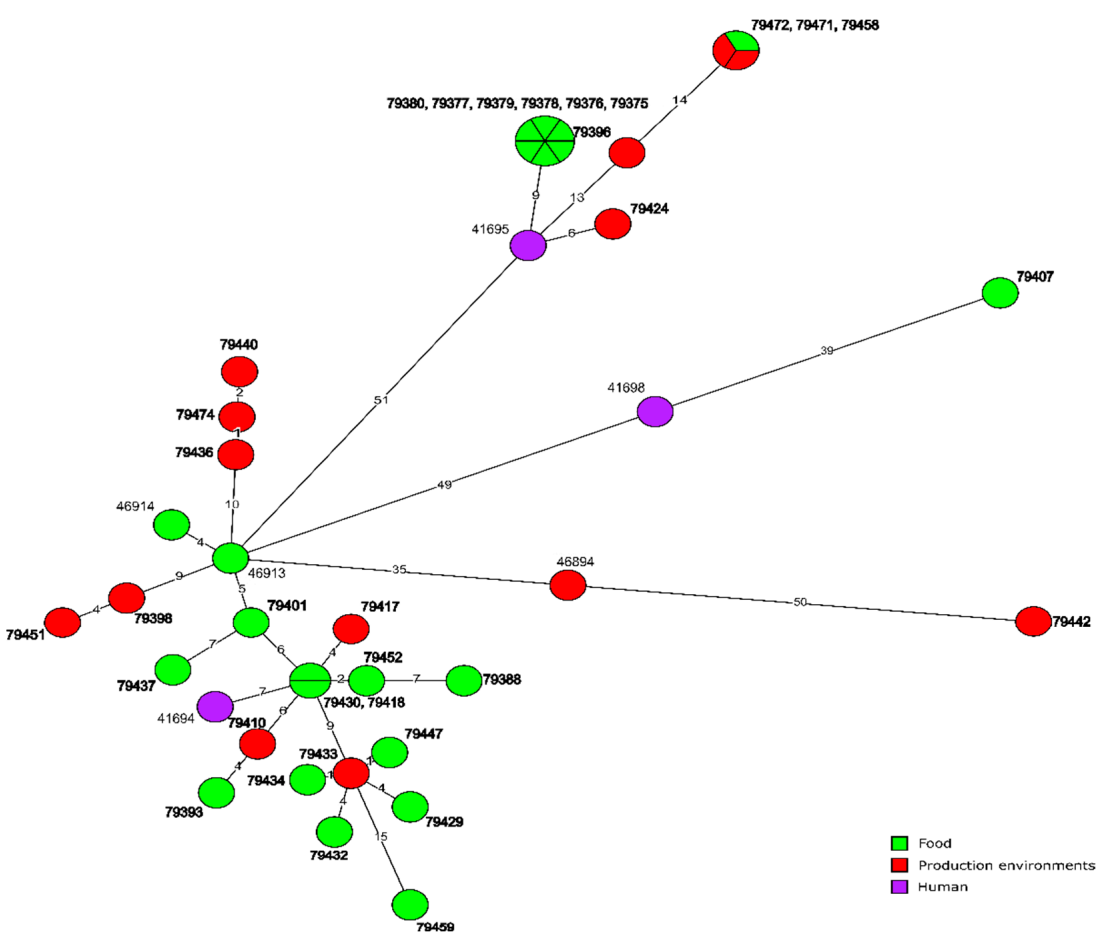

Figure 4. Minimum spanning tree (MST) based on the cgMLST profiles of L. monocytogenes CC155 tested in the present study with publicly available six strains of CC155 from Poland. The Source of the isolates are represented by colored circles where the size is proportional to the number of strains. Numbers on the branches show alleles differences between neighboring nodes (CTs). The strain numbers in bold represent L. monocytogenes isolates from the present study.

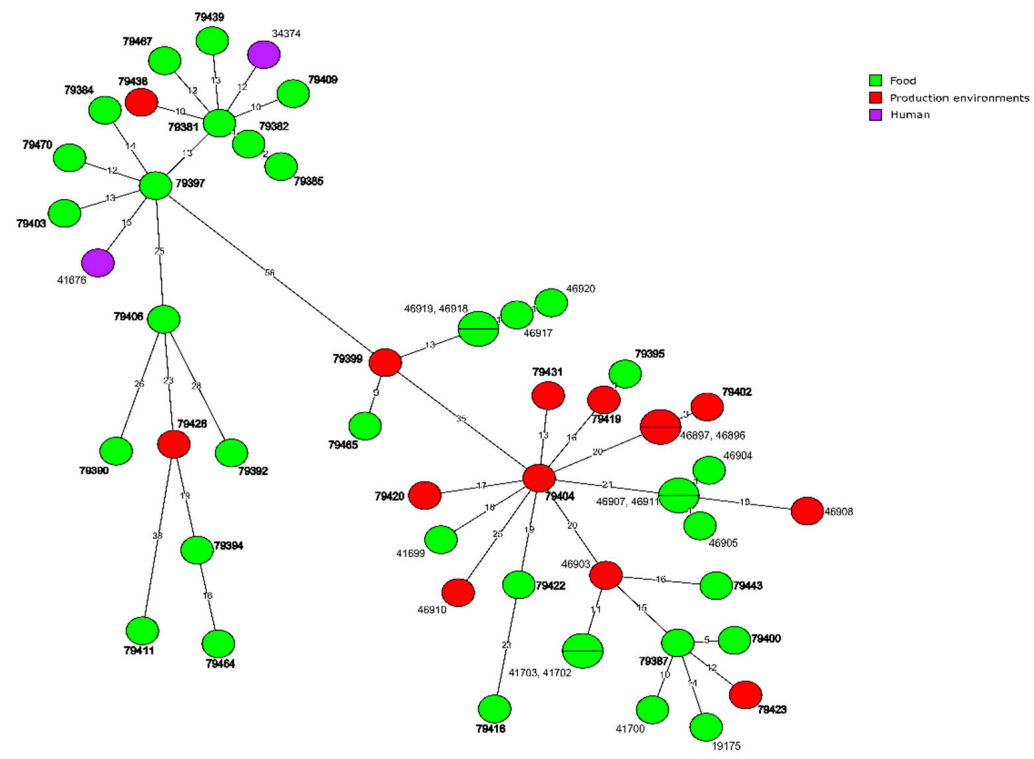

Figure 5. Minimum spanning tree (MST) based on the cgMLST profiles of L. monocytogenes CC121 tested in the present study with publicly available 20 strains of CC121 from Poland. Source of the isolates are represented by colored circles where the size is proportional to the number of strains. Numbers on the branches show alleles differences between neighboring nodes (CTs). The strain numbers in bold represent L. monocytogenes isolates from the present study. 


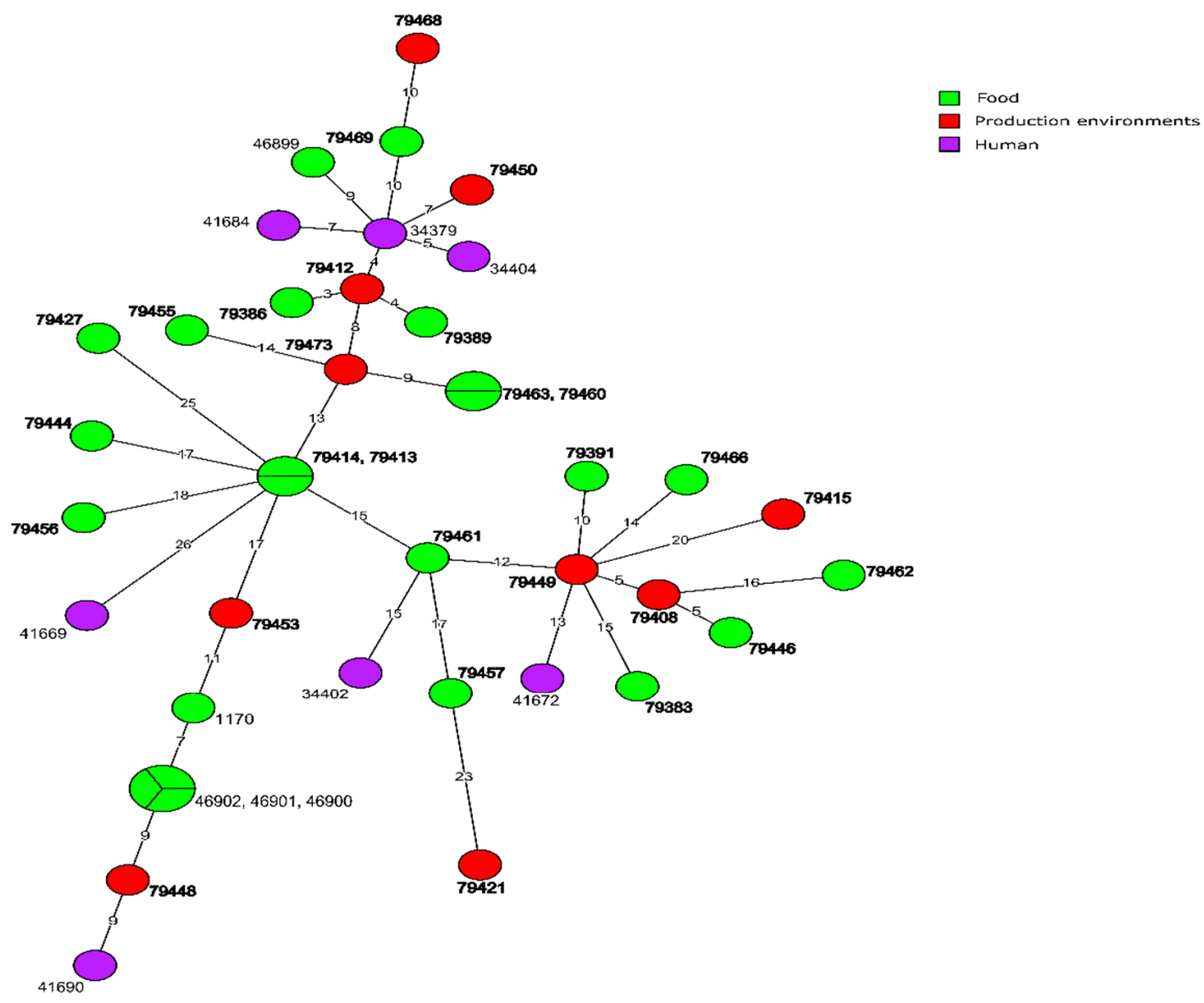

Figure 6. Minimum spanning tree (MST) based on the cgMLST profiles of L. monocytogenes CC8 tested in the present study with publicly available twelve strains of CC8 from Poland. Source of the isolates are represented by colored circles where the size is proportional to the number of strains. Numbers on the branches show alleles differences between neighboring nodes (CTs). The strain numbers in bold represent L. monocytogenes isolates from the present study.

Analysis of genetic similarity of the remaining L. monocytogenes strains classified to CC7, CC11, and CC37 showed that only one currently tested isolate (ID79454 of CC11, recovered from RTE food in 2018 in warmińsko-mazurskie voivodeship) showed a three allelic difference with one strain (ID41692) isolated in 2015 from a person suffering from listeriosis.

\section{Conclusions}

WGS analysis of L. monocytogenes classified to serogroup IIa, isolated from food and food production environments in Poland, revealed a prevalence of several resistance and virulence genes among the isolates tested. Identification of certain genetic traits, especially those encoding resistance to disinfectants and responsible for biofilm formation as well as isolation of the strains with the same molecular profiles in different years from the same geographical areas, suggest that at least some of the L. monocytogenes tested possess the ability to persist in food production environments for a long time. The investigated isolates showed a high genotypic diversity as identified during the analysis of the WGS data, especially based on the cgMLST sequences. A close molecular relationship of the current $L$. monocytogenes isolates tested with those recovered previously from similar food and food production sources and from patients with listeriosis indicate that foods and their production environments may be a potential source of pathogenic strains for humans.

Supplementary Materials: The following supporting information can be downloaded at: https: / / www.mdpi.com/article/10.3390/microorganisms10030532/s1, Figure S1: Phylogenetic tree of all 100 L. monocytogenes isolated tested; Figure S2: Comparison of L. monocytogenes CC155 isolates; Figure S3: Comparison of L. monocytogenes CC121 isolates; Figure S4: Comparison of L. monocytogenes 
CC8 isolates; Table S1: Characteristics of L. monocytogenes isolates tested; Table S2: L. monocytogenes sequence parameters.; Table S3: L. monocytogenes isolates from Poland selected for comparison with the present strains; Table S4: Prophages and plasmids in Listeria monocytogenes strains tested.

Author Contributions: B.L. and K.W., Conceptualization, visualization, investigation, methodology development, formal analysis and validation; K.W., Supervision; B.L. Original draft writing; K.W. and J.O., Final writing, review, and editing. All authors have read and agreed to the published version of the manuscript.

Funding: The study was funded by the National Veterinary Research Institute (NVRI), Pulawy, Poland within the "NVRI Research Fund" awarded to project no. F/116.

Institutional Review Board Statement: Not applicable.

Informed Consent Statement: Not applicable.

Data Availability Statement: The genome sequences obtained in the present study were deposited in the Listeria PasteurMLST database (https:/ / bigsdb.pasteur.fr/listeria (accessed on 15 January 2022)) under the accession numbers 79375-79474.

Acknowledgments: The authors thank Alexandra Moura (Pasteur Institute, Paris, France) for assistance with Listeria MLST system (http:/ / bigsdb.pasteur.fr (accessed on 15 January 2022)). We also thank the staff of Department of Omics Analyses at NVRI, Pulawy for expert technical support.

Conflicts of Interest: The authors declare no conflict of interest.

\section{References}

1. Burall, L.S.; Grim, C.J.; Mammel, M.K.; Datta, A.R. Whole genome sequence analysis using JSpecies tool establishes clonal relationships between Listeria monocytogenes strains from epidemiologically unrelated listeriosis outbreaks. PLoS ONE 2016, 11, e0150797. [CrossRef] [PubMed]

2. Burall, L.S.; Grim, C.J.; Datta, A.R. A clade of Listeria monocytogenes serotype $4 \mathrm{~b}$ variant strains linked to recent listeriosis outbreaks associated with produce from a defined geographic region in the US. PLoS ONE 2017, 12, e0176912. [CrossRef] [PubMed]

3. Henri, C.; Leekitcharoenphon, P.; Carleton, H.A.; Radomski, N.; Kaas, R.S.; Mariet, J.F.; Felten, A.; Aarestrup, F.M.; Gerner Smidt, P.; Roussel, S.; et al. An assessment of different genomic approaches for inferring phylogeny of Listeria monocytogenes. Front. Microbiol. 2017, 8, 2351. [CrossRef] [PubMed]

4. Hyden, P.; Pietzka, A.; Lennkh, A.; Murer, A.; Springer, B.; Blaschitz, M.; Indra, A.; Huhulescu, S.; Allerberger, F.; Ruppitsch, W.; et al. Whole genome sequence-based serogrouping of Listeria monocytogenes isolates. J. Biotechnol. 2016, 235, 181-186. [CrossRef]

5. EFSA (European Food Safety Authority); ECDC (European Centre for Disease Prevention and Control). The European Union One Health 2020 Zoonoses Report. EFSA J. 2021, 19, 6971. [CrossRef]

6. $\quad$ Buchanan, R.L.; Gorris, L.G.M.; Hayman, M.M.; Jackson, T.C.; Whiting, R.C. A review of Listeria monocytogenes: An update on outbreaks, virulence, dose-response, ecology, and risk assessments. Food Control 2017, 75, 1-13. [CrossRef]

7. Ranasinghe, R.A.S.S.; Satharasinghe, D.A.; Tang, J.Y.H.; Rukayadi, Y.; Radu, K.R.; New, C.Y.; Son, R.; Premarathne, J.M.K.J.K. Persistence of Listeria monocytogenes in food commodities: Foodborne pathogenesis, virulence factors, and implications for public health. Food Res. 2021, 5, 1-16. [CrossRef]

8. Doumith, M.; Buchrieser, C.; Glaser, P.; Jacquet, C.; Martin, P. Differentiation of the major Listeria monocytogenes serovars by multiplex PCR. J. Clin. Microbiol. 2004, 42, 3819-3822. [CrossRef]

9. Matle, I.; Mbatha, K.R.; Madoroba, E. A review of Listeria monocytogenes from meat and meat products: Epidemiology, virulence factors, antimicrobial resistance and diagnosis. Onderstepoort J. Vet. Res. 2020, 87, a1869. [CrossRef]

10. Orsi, R.H.; den Bakker, H.C.; Wiedmann, M. Listeria monocytogenes lineages: Genomics, evolution, ecology, and phenotypic characteristics. Int. J. Med. Microbiol. 2011, 301, 79-96. [CrossRef]

11. Moura, A.; Criscuolo, A.; Pouseele, H.; Maury, M.M.; Leclercq, A.; Tar, C.; Björkman, J.T.; Dallman, T.; Reimer, A.; Enouf, V.; et al. Whole genome-based population biology and epidemiological surveillance of Listeria monocytogenes. Nat. Microbiol. 2016, 2, 16185. [CrossRef]

12. Zhang, H.; Chen, W.; Wang, J.; Xu, B.; Liu, H.; Dong, Q.; Zhang, X. 10-year molecular surveillance of Listeria monocytogenes using whole-genome sequencing in Shanghai, China, 2009-2019. Front. Microbiol. 2020, 11, 551020. [CrossRef]

13. Alvarez-Molina, A.; Cobo-Díaz, J.F.; López, M.; Prieto, M.; de Toro, M.; Alvarez-Ordóñez, A. Unraveling the emergence and population diversity of Listeria monocytogenes in a newly built meat facility through whole genome sequencing. Int. J. Food Microbiol. 2021, 340, 109043. [CrossRef]

14. Wang, Y.; Ji, Q.; Li, S.; Liu, M. Prevalence and genetic diversity of Listeria monocytogenes isolated from retail pork in Wuhan, China. Front. Microbiol. 2021, 12, 620482. [CrossRef] 
15. Hurley, D.; Luque-Sastre, L.; Parker, C.T.; Huynh, S.; Eshwar, A.K.; Nguyen, S.V.; Andrews, N.; Moura, A.; Fox, E.M.; Jordan, K.; et al. Whole-genome sequencing-based characterization of 100 Listeria monocytogenes isolates collected from food processing environments over a four-year period. mSphere 2019, 4, e00252-19. [CrossRef]

16. Jagadeesan, B.; Baert, L.; Wiedmann, M.; Orsi, R.H. Comparative analysis of tools and approaches for source tracking Listeria monocytogenes in a food facility using whole-genome sequence data. Front. Microbiol. 2019, 10, 947. [CrossRef]

17. Orsi, R.H.; Jagadeesan, B.; Baert, L.; Wiedmann, M. Identification of closely related Listeria monocytogenes isolates with no apparent evidence for a common source or location: A retrospective whole genome sequencing analysis. J. Food Prot. 2021, 84, $1104-1113$. [CrossRef]

18. Bergholz, T.M.; Shah, M.K.; Burall, L.S.; Rakic-Martinez, M.; Datta, A.R. Genomic and phenotypic diversity of Listeria monocytogenes clonal complexes associated with human listeriosis. Appl. Microbiol. Biotechnol. 2018, 102, 3475-3485. [CrossRef]

19. Palma, F.; Brauge, T.; Radomski, N.; Mallet, L.; Felten, A.; Mistou, M.Y.; Brisabois, A.; Guillier, L.; Midelet-Bourdin, G. Dynamics of mobile genetic elements of Listeria monocytogenes persisting in ready-to-eat seafood processing plants in France. BMC Genom. 2020, 21, 130. [CrossRef]

20. Sévellec, Y.; Torresi, M.; Félix, B.; Palma, F.; Centorotola, G.; Bilei, S.; Senese, M.; Terracciano, G.; Leblanc, J.C.; Pomilio, F.; et al. First report on the finding of Listeria mnocytogenes ST121 strain in a dolphin brain. Pathogens 2020, 9, 802. [CrossRef]

21. Wagner, E.; Zaiser, A.; Leitner, R.; Quijada, N.M.; Pracser, N.; Pietzka, A.; Ruppitsch, W.; Schmitz-Esser, S.; Wagner, M.; Rychli, K. Virulence characterization and comparative genomics of Listeria monocytogenes sequence type 155 strains. BMC Genom. 2020, 21, 847. [CrossRef] [PubMed]

22. Jolley, K.A.; Maiden, M.C.J. BIGSdb: Scalable analysis of bacterial 780 genome variation at the population level. BMC Bioinform. 2010, 11, 595. [CrossRef] [PubMed]

23. Moura, A.; Tourdjman, M.; Leclercq, A.; Hamelin, E.; Laurent, E.; Fredriksen, N.; Van Cauteren, D.; Bracq-Dieye, H.; Thouvenot, P.; Vales, G.; et al. Real-time whole-genome sequencing for surveillance of Listeria monocytogenes, France. Emerg. Infect. Dis. 2017, 23, 1462-1470. [CrossRef] [PubMed]

24. Schubert, W.D.; Urbanke, C.; Ziehm, T.; Beier, V.; Machner, M.P.; Domann, E.; Wehland, J.; Chakraborty, T.; Heinz, D.W. Structure of internalin, a major invasion protein of Listeria monocytogenes, in complex with its human receptor E-cadherin. Cell 2002, 111, 825-836. [CrossRef]

25. Franciosa, G.; Maugliani, A.; Scalfaro, C.; Floridi, F.; Aureli, P. Expression of internalin A and biofilm formation among Listeria monocytogenes clinical isolates. Int. J. Immunopathol. Pharmacol. 2009, 22, 183-193. [CrossRef]

26. Meier, A.B.; Guldimann, C.; Markkula, A.; Pöntinen, A.; Korkeala, H.; Tasara, T. Comparative phenotypic and genotypic analysis of Swiss and Finnish Listeria monocytogenes isolates with respect to benzalkonium chloride resistance. Front. Microbiol. $2017,8,397$. [CrossRef]

27. Ortiz, S.; López-Alonso, V.; Rodríguez, P.; Martínez-Suárez, J.V. The connection between persistent, disinfectant-resistant Listeria monocytogenes strains from two geographically separate Iberian pork processing plants: Evidence from comparative genome analysis. Appl. Environ. Microbiol. 2016, 82, 308-317. [CrossRef]

28. Kropac, A.C.; Eshwar, A.K.; Stephan, R.; Tasara, T. New insights on the role of the pLMST6 plasmid in Listeria monocytogenes biocide tolerance and virulence. Front. Microbiol. 2019, 10, 1538. [CrossRef]

29. ISO 11290-1:2017; Microbiology of the Food Chain-Horizontal Method for the Detection and Enumeration of Listeria monocytogenes and of Listeria spp.-Part 1: Detection Method. International Organization for Standardization: Geneva, Switzerland, 2017.

30. Lachtara, B.; Osek, J.; Wieczorek, W. Molecular typing of Listeria monocytogenes IVb serogroup isolated from food and food production environments in Poland. Pathogens 2021, 10, 482. [CrossRef]

31. Bolger, A.M.; Lohse, M.; Usadel, B. Trimmomatic: Aflexible trimmer for Illumina sequence data. Bioinformatics 2014, 30, 2114-2120. [CrossRef]

32. Bankevich, A.; Nurk, S.; Antipov, D.; Gurevich, A.; Dvorkin, M.; Kulikov, A.S.; Lesin, V.; Nikolenko, S.; Pham, S.; Prjibelski, A.; et al. SPAdes: A new genome assembly algorithm and its applications to single-cell sequencing. J. Comput. Biol. 2012, 19, 455-477. [CrossRef]

33. Maury, M.M.; Tsai, Y.H.; Charlier, C.; Touchon, M.; Chenal-Francisque, V.; Leclercq, A.; Criscuolo, A.; Gaultier, C.; Roussel, S.; Brisabois, A.; et al. Uncovering Listeria monocytogenes hypervirulence by harnessing its biodiversity. Nat. Genet. 2016, 48, 308-313. [CrossRef]

34. Ragon, M.; Wirth, T.; Hollandt, F.; Lavenir, R.; Lecuit, M.; Le Monnier, A.; Brisse, S.A. New perspective on Listeria monocytogenes evolution. PLoS Pathog. 2008, 4, e1000146. [CrossRef]

35. Gilmour, M.W.; Graham, M.; Van Domselaar, G.; Tyler, S.; Kent, H.; Trout-Yakel, K.M.; Larios, O.; Allen, V.; Lee, B.; Nadon, C. High-throughput genome sequencing of two Listeria monocytogenes clinical isolates during a large foodborne outbreak. BMC Genom. 2010, 11, 120. [CrossRef]

36. Harter, E.; Wagner, E.M.; Zaiser, A.; Halecker, S.; Wagner, M.; Rychli, K. Stress Survival Islet 2, predominantly present in Listeria monocytogenes strains of sequence type 121, is involved in the alkaline and oxidative stress responses. Appl. Environ. Microbiol. 2017, 83, e00827-17. [CrossRef]

37. Ryan, S.; Begley, M.; Hill, C.; Gahan, C.G.M. A five-gene stress survival islet (SSI-1) that contributes to the growth of Listeria monocytogenes in suboptimal conditions. J. Appl. Microbiol. 2010, 109, 984-995. [CrossRef] 
38. Zhang, J.; Cao, G.; Xu, X.; Allard, M.; Li, P.; Brown, E.; Yang, X.; Pan, H.; Meng, J. Evolution and diversity of Listeria monocytogenes from clinical and food samples in Shanghai, China. Front. Microbiol. 2016, 7, 1138. [CrossRef]

39. Kremer, P.H.; Lees, J.A.; Koopmans, M.M.; Ferwerda, B.; Arends, A.W.; Feller, M.M.; Schipper, K.; Valls Seron, M.; van der Ende, A.; Brouwer, M.C.; et al. Benzalkonium tolerance genes and outcome in Listeria monocytogenes meningitis. Clin. Microbial. Infect. 2017, 23, 265.e1-265.e7. [CrossRef]

40. Møretrø, T.; Schirmer, B.; Heir, E.; Fagerlund, A.; Hjemli, P.; Langsrud, S. Tolerance to quaternary ammonium compound disinfectants may enhance growth of Listeria monocytogenes in the food industry. Int. J. Food Microbiol. 2017, 241, $215-224$. [CrossRef]

41. Arndt, D.; Grant, J.; Marcu, A.; Sajed, T.; Pon, A.; Liang, Y.; Wishart, D.S. PHASTER: A better, faster version of the PHAST phage search tool. Nucleic Acids Res. 2016, 44, 16-21. [CrossRef]

42. Zhou, Y.; Liang, Y.; Lynch, K.H.; Dennis, J.J.; Wishart, D.S. PHAST: A fast phage search tool. Nucleic Acids Res. 2011, 39, W347-W352. [CrossRef] [PubMed]

43. Carattoli, A.; Zankari, E.; García-Fernández, A.; Voldby Larsen, M.; Lund, O.; Villa, L.; Møller Aarestrup, F.; Hasman, H. In silico detection and typing of plasmids using PlasmidFinder and plasmid multilocus sequence typing. Antimicrob. Agents Chemother. 2014, 58, 3895-3903. [CrossRef] [PubMed]

44. EFSA BIOHAZ Panel (EFSA Panel on Biological Hazards); Ricci, A.; Allende, A.; Bolton, D.; Chemaly, M.; Davies, R.; Escámez, P.S.F.; Girones, R.; Herman, L.; Koutsoumanis, K.; et al. Scientific opinion on the Listeria monocytogenes contamination of ready-to-eat foods and the risk for human health in the EU. EFSA J. 2018, 16, 5134. [CrossRef]

45. Fischer, M.A.; Thürmer, A.; Flieger, A.; Halbedel, S. Complete genome sequences of three clinical Listeria monocytogenes sequence type 8 strains from recent German listeriosis outbreaks. Microbiol. Resour. Announc. 2021, 10, e00303-21. [CrossRef] [PubMed]

46. Li, W.; Bai, L.; Fu, P.; Han, H.; Liu, J.; Guo, Y. The epidemiology of Listeria monocytogenes in China. Foodborne Pathog. Dis. 2018, 15, 459-466. [CrossRef] [PubMed]

47. Zhang, X.; Liu, Y.; Zhang, P.; Niu, Y.; Chen, Q.; Ma, X. Genomic characterization of clinical Listeria monocytogenes isolates in Beijing, China. Front. Microbiol. 2021, 12, 751003. [CrossRef]

48. Kurpas, M.; Osek, J.; Moura, A.; Leclercq, A.; Lecuit, M.; Wieczorek, K. Genomic characterization of Listeria monocytogenes isolated from ready-to-eat meat and meat processing environments in Poland. Front. Microbiol. 2020, 11, 1412. [CrossRef]

49. Shi, D.; Anwar, T.M.; Pan, H.; Chai, W.; Xu, S.; Yue, M. Genomic determinants of pathogenicity and antimicrobial resistance for 60 global Listeria monocytogenes isolates responsible for invasive infections. Front. Cell. Infect. Microbiol. 2021, 11, 718840. [CrossRef]

50. Gouin, E.; Mengaud, J.; Cossart, P. The virulence gene cluster of Listeria monocytogenes is also present in Listeria ivanovii, an animal pathogen, and Listeria seeligeri, a nonpathogenic species. Infect. Immun. 1994, 62, 3550-3553. [CrossRef]

51. Disson, O.; Moura, A.; Lecuit, M. Making sense of the biodiversity and virulence of Listeria monocytogenes. Trends Microbiol. 2021, 11, 811-822. [CrossRef]

52. Parsons, C.; Lee, S.; Kathariou, S. Heavy metal resistance determinants of the foodborne pathogen Listeria monocytogenes. Genes 2019, 10, 11. [CrossRef]

53. Chmielowska, C.; Korsak, D.; Szuplewska, M.; Grzelecka, M.; Maćkiw, E.; Stasiak, M.; Macion, A.; Skowron, K.; Bartosik, D Benzalkonium chloride and heavy metal resistance profiles of Listeria monocytogenes strains isolated from fish, fish products and food-producing factories in Poland. Food Microbiol. 2021, 98, 103756. [CrossRef]

54. Ratani, S.S.; Siletzky, R.M.; Dutta, V.; Yildirim, S.; Osborne, J.; Lin, W.; Hitchins, A.D.; Ward, T.J.; Kathariou, S. Heavy metal and disinfectant resistance of Listeria monocytogenes from foods and food processing plants. Appl. Environ. Microbiol. 2012, 78, 6938-6945. [CrossRef]

55. Bucur, F.I.; Grigore-Gurgu, L.; Crauwels, P.; Riedel, C.U.; Nicolau, A.I. Resistance of Listeria monocytogenes to stress conditions encountered in food and food processing environments. Front. Microbiol. 2018, 9, 2700. [CrossRef]

56. O'Byrne, C.P.; Karatzas, K.A. The role of sigma B (sB) in the stress adaptations of Listeria monocytogenes: Overlaps between stress adaptation and virulence. Adv. Appl. Microbiol. 2008, 65, 115-140. [CrossRef]

57. Mohan, V.; Cruz, C.D.; van Vliet, A.H.M.; Pitman, A.R.; Visnovsky, S.B.; Rivas, L.; Gilpin, B.; Fletcher, G.C. Genomic diversity of Listeria monocytogenes isolates from seafood, horticulture and factory environments in New Zealand. Int. J. Food Microbiol. 2021, 347, 109166. [CrossRef]

58. Mafuna, T.; Matle, I.; Magwedere, K.; Pierneef, R.E.; Reva, O.N. Whole genome-based characterization of Listeria monocytogenes isolates recovered from the food chain in South Africa. Front. Microbiol. 2021, 12, 669287. [CrossRef]

59. Rychli, K.; Wagner, E.M.; Ciolacu, L.; Zaiser, A.; Tasara, T.; Wagner, M.; Schmitz-Esser, S. Comparative genomics of human and non-human Listeria monocytogenes sequence type 121 strains. PLoS ONE 2017, 12, e0176857. [CrossRef]

60. Vu, H.T.K.; Benjakul, S.; Vongkamjan, K. Characterization of Listeria prophages in lysogenic isolates from foods and food processing environments. PLoS ONE 2019, 14, e0214641. [CrossRef]

61. Casey, A.; Jordan, K.; Neve, H.; Coffey, A.; McAuliffe, O. A tail of two phages: Genomic and functional analysis of Listeria monocytogenes phages vB_LmoS_188 and vB_LmoS_293 reveal the receptor-binding proteins involved in host specificity. Front. Microbiol. 2015, 6, 1107. [CrossRef] 
62. Denes, T.; Vongkamjan, K.; Ackermann, H.W.; Moreno Switt, A.I.; Wiedmann, M.; den Bakker, H.C. Comparative genomic and morphological analyses of Listeria phages isolated from farm environments. Appl. Environ. Microbiol. 2014, 80, 4616-4625. [CrossRef] [PubMed]

63. Matle, I.; Pierneef, R.; Mbatha, K.R.; Magwedere, K.; Madoroba, E. Genomic diversity of common sequence types of Listeria monocytogenes isolated from ready-to-eat products of animal origin in South Africa. Genes 2019, 10, 1007. [CrossRef] [PubMed]

64. Kuenne, C.; Billion, A.; Mraheil, M.A.; Strittmatter, A.; Daniel, R.; Goesmann, A.; Barbuddhe, S.; Hain, T.; Chakraborty, T. Reassessment of the Listeria monocytogenes pan-genome reveals dynamic integration hotspots and mobile genetic elements as major components of the accessory genome. BMC Genom. 2013, 14, 1-19. [CrossRef] [PubMed]

65. Rabinovich, L.; Sigal, N.; Borovok, I.; Nir-Paz, R.; Herskovits, A.A. Prophage excision activates Listeria competence genes that promote phagosomal escape and virulence. Cell 2012, 150, 792-802. [CrossRef]

66. Duze, S.T.; Marimani, M.; Patel, M. Tolerance of Listeria monocytogenes to biocides used in food processing environments. Food Microbiol. 2021, 97, 103758. [CrossRef]

67. Dutta, V.; Elhanafi, D.; Kathariou, S. Conservation and distribution of the benzalkonium chloride resistance cassette bcrABC in Listeria monocytogenes. Appl. Environ. Microbiol. 2013, 79, 6067-6074. [CrossRef]

68. Müller, A.; Rychli, K.; Zaiser, A.; Wieser, C.; Wagner, M.; Schmitz-Esser, S. The Listeria monocytogenes transposon Tn6188 provides increased tolerance to various quaternary ammonium compounds and ethidium bromide. FEMS Microbiol. Lett. 2014, 361, 166-173. [CrossRef]

69. Keeney, K.; Trmcic, A.; Zhu, Z.; Delaquis, P.; Wang, S. Stress survival islet 1 contributes to serotype-specific differences in biofilm formation in Listeria monocytogenes. Lett. Appl. Microbiol. 2018, 67, 530-536. [CrossRef]

70. Matereke, L.T.; Okoh, A.I. Listeria monocytogenes virulence, antimicrobial resistance and environmental persistence: A review. Pathogens 2020, 9, 528. [CrossRef]

71. Palaiodimou, L.; Fanning, S.; Fox, E.M. Genomic insights into persistence of Listeria species in the food processing environment. J. Appl. Microbiol. 2021, 131, 2082-2094. [CrossRef]

72. Gilmartin, N.; Gião, M.S.; Keevil, C.W.; O'Kennedy, R. Differential internalin A levels in biofilms of Listeria monocytogenes grown on different surfaces and nutrient conditions. Int. J. Food Microbiol. 2016, 219, 50-55. [CrossRef]

73. Nightingale, K.K.; Windham, K.; Martin, K.E.; Yeung, M.; Wiedmann, M. Select Listeria monocytogenes subtypes commonly found in foods carry distinct nonsense mutations in inlA, leading to expression of truncated and secreted internalin A, and are associated with a reduced invasion phenotype for human intestinal epithelial cells. Appl. Environ. Microbiol. 2005, 71, 8764-8772. [CrossRef]

74. Naditz, A.L.; Dzieciol, M.; Wagner, M.; Schmitz-Esser, S. Plasmids contribute to food processing environment-associated stress survival in three Listeria monocytogenes ST121, ST8, and ST5 strains. Int. J. Food Microbiol. 2019, 299, 39-46. [CrossRef]

75. Schmitz-Esser, S.; Müller, A.; Stessl, B.; Wagner, M. Genomes of sequence type 121 Listeria monocytogenes strains harbor highly conserved plasmids and prophages. Front. Microbiol. 2015, 6, 380. [CrossRef]

76. Horlbog, J.A.; Kent, D.; Stephan, R.; Guldimann, C. Surviving host and food relevant stresses: Phenotype of L. monocytogenes strains isolated from food and clinical sources. Sci. Rep. 2018, 8, 12931. [CrossRef]

77. Maury, M.M.; Bracq-Dieye, H.; Huang, L.; Vales, G.; Lavina, M.; Thouvenot, P.; Disson, O.; Leclercq, A.; Brisse, S.; Lecuit, M. Hypervirulent Listeria monocytogenes clones' adaption to mammalian gut accounts for their association with dairy products. Nat. Commun. 2019, 10, 2488. [CrossRef]

78. Kovacevic, J.; Ziegler, J.; Wałecka-Zacharska, E.; Reimer, A.; Kitts, D.D.; Gilmour, M.W. Tolerance of Listeria monocytogenes to quaternary ammonium sanitizers is mediated by a novel efflux pump encoded by emrE. Appl. Environ. Microbiol. 2016, 82, 939-953. [CrossRef]

79. Fagerlund, A.; Langsrud, S.; Schirmer, B.C.T.; Møretrø, T.; Heir, E. Genome analysis of Listeria monocytogenes sequence type 8 strains persisting in salmon and poultry processing environments and comparison with related strains. PLOS ONE 2016, 11, e0151117. [CrossRef]

80. Wieczorek, K.; Bomba, A.; Osek, J. Whole-genome sequencing-based characterization of Listeria monocytogenes from fish and fish production environments in Poland. Int. J. Mol. Sci. 2020, 21, 9419. [CrossRef]

81. Bergholz, T.M.; den Bakker, H.C.; Katz, L.S.; Silk, B.J.; Jackson, K.A.; Kucerova, Z.; Joseph, L.A.; Turnsek, M.; Gladney, L.M.; Halpin, J.L.; et al. Determination of evolutionary relationships of outbreak-associated Listeria monocytogenes strains of serotypes 1/2a and 1/2b by whole-genome sequencing. Appl. Environ. Microbiol. 2016, 82, 928-938. [CrossRef]

82. European Centre for Disease Prevention and Control and European Food Safety Authority. Multi-Country Outbreak of Listeria monocytogenes Clonal Complex 8 Infections Linked to Consumption of Cold-Smoked Fish Products—4 June 2019; ECDC: Stockholm, Sweden; EFSA: Parma, Italy, 2019. [CrossRef]

83. European Centre for Disease Prevention and Control and European Food Safety Authority. Multi-Country Outbreak of Listeria monocytogenes Sequence Type 8 Infections Linked to Consumption of Salmon Products-25 October 2018; ECDC: Stockholm, Sweden; EFSA: Parma, Italy, 2018. [CrossRef]

84. Borucki, M.K.; Peppin, J.D.; White, D.; Loge, F.; Call, D.R. Variation in biofilm formation among strains of Listeria monocytogenes. Appl. Environ. Microbiol. 2003, 69, 7336-7342. [CrossRef] [PubMed]

85. Takahashi, H.; Miya, S.; Igarashi, K.; Suda, T.; Kuramoto, S.; Kimura, B. Biofilm formation ability of Listeria monocytogenes isolates from raw ready-to-eat seafood. J. Food Prot. 2009, 72, 1476-1480. [CrossRef] [PubMed] 
86. Raschle, S.; Stephan, R.; Stevens, M.; Cernela, N.; Zurfluh, K.; Muchaamba, F.; Nüesch-Inderbinen, M. Environmental dissemination of pathogenic Listeria monocytogenes in flowing surface waters in Switzerland. Sci. Rep. 2021, 11, 9066. [CrossRef] [PubMed]

87. Šteingolde, Ž.; Meistere, I.; Avsejenko, J.; Kibilds, J.; Bergšpica, I.; Streikiša, M.; Gradovska, S.; Alksne, L.; Roussel, S.; Terentjeva M.; et al. Characterization and genetic diversity of Listeria monocytogenes isolated from cattle abortions in Latvia, 2013-2018. Vet. Sci. 2021, 8, 195. [CrossRef] 